\title{
Neural Blockade in Cervical Pain Syndromes
}

Laxmaiah Manchikanti, M.D.

Pain Management Center of Paducah, Paducah, KY

Chronic neck pain, headache, and arm pain are some of the most common patient complaints confronting today's health care provider. Chronic neck pain is reported to be a frequency symptom in $34 \%$ of the general population with $14 \%$ of the general population reporting neck pain that lasted for more than 6 months. The magnitude of the problem is demonstrated by increase of cervical spine surgery by $45 \%$ and cervical fusion by $70 \%$ over a ten year period from 1979 through 1988. Therapeutic effectiveness of a large variety of interventions in managing chronic neck pain is inconclusive. Pain and dysfunction have been attributed to a number of structure in the neck which have a potential for producing a pain pattern in the neck, head, and upper extremity which include intervertebral disc, nerve roots, facet joints, and

Cervical pain syndromes are some of the most common patient complaints confronting the healthcare provider and include neck pain, headache, and arm pain (1-8). Pain in the neck is an everyday event, though not as common or disabling as low back pain. Bovim et al(3) estimated that chronic neck pain is a frequent symptom in the general population with a total of $34 \%$ reporting neck pain and $14 \%$ of the total group studied reporting neck pain that lasted for more than 6 months. It is also stated that, even though, cervical disc herniation and cervical spondylosis contribute to a small percentage of patients with neck pain, cervical spine surgery increased over $45 \%$, while cervical fusion surgery increased over $70 \%$ from $1979-81$ to 1988 90(8). Chronic neck pain and headache are common entities after whiplash injury (4). In fact, cervicogenic headache has been described in $14 \%$ to $18 \%$ of the total headache population with an incidence of approximately $1 \%$ in general population $(5-7,9)$. Numerous therapeutic interventions have been described for the treatment of chronic neck pain and associated syndromes including surgery, drugs, manipulation, physical therapy, behavior therapy, and neural blockade. However, the effectiveness of a large variety of therapeutic interventions in managing chronic neck pain has not been demonstrated conclusively(4, 8, 10-19). Even though neural blockade has been used widely for the relief of chronic low back pain for almost a century,

Address Correspondence: Laxmaiah Manchikanti, M.D., Pain Management Center of Paducah, 2831 Lone Oak Road, Paducah, KY 42003 ligamentous and muscular structures.

Neural blockade in the cervical spine, though introduced in 1912, lagged behind that of the lumbar spine. At the present time, neural blockade is an extremely popular tool for diagnostic purposes in evaluation of neck pain, even though it has not developed a definitive role in the management of chronic neck pain and associated syndromes. The object of this review is to focus on various aspects of neural blockade in the management of chronic neck pain and associated syndromes including its rationale, clinical effectiveness, indications, and complications. Keywords: Neck Pain, Headache, Facet Joints, Neural Blockade, Epidural Steroids, Facet Joint Injections

its usage in the management of chronic neck pain lagged behind. The evidence shows that chronic neck pain, associated with various pathologic and degenerative disorders is managed effectively with neural blockade(20-40). The object of this review is to focus on various aspects of neural blockade in the management of chronic neck pain.

\section{PATHOPHYSIOLOGICAL ASPECTS}

Neck pain is by definition pain that is perceived by the patient as existing primarily in the axial region of the body; that includes the dorsal area from the base of the occiput to the mid upper interscapular region of the back. In contrast, arm pain is experienced as a result of radiculitis or radiculopathy emanating from the region of the neck and traveling distally in a definite pathway into the upper extremity. Cervicogenic headache involves musculoskeletal tissues innervated by cervical nerves as the primary nociceptive source of the referred pain perceived in any region of the head.

Despite the prevalence of chronic neck pain, its pathophysiology remains poorly understood, both in the presence and absence of structural pathology(41). The search for pathophysiology of chronic neck pain was met with lack of significant structural abnormality by imaging, lack of significant relationship between degenerative changes and pain intensity, and the presence of significant cervical spondylosis in asymptomatic individuals $(2,41,42)$. 


\section{$D^{\text {ssfunction }}$}

Normal

Small annular tears

Annular tears

$D^{\text {iscogenic }}$

Spondylosis

Qtabilization
Disc herniation

Disc degeneration

Endplate sclerosis

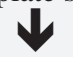

Loss of disc height

$\sqrt{4}$

Loss of lordosis

Uncinate hypertrophy

Spondylolytic bars
Foraminal stenosis
Muscular sprain

Facet synovitis

Capsular laxity

Capsular tears

Pseudosubluxation

Facet osteophytosis

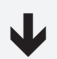

Loss of cartilage endplate

Subluxation
Increase in vertebral body diameter

Decrease in canal diameter

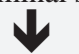

Flattening of spinal cord

Vascular infarction of spinal cord
Facet arthrosis

Ligamentum flavum hypertrophy

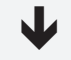

Foraminal stenosis

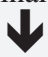

Posterior cord impingement

Figure 1. The spectrum of interaction of facet joint and disc changes in three joint complex. Adapted and modified from Handel, et al (51).

A number of structures in the neck have the potential for producing a pain pattern in the neck, head, and upper extremity. Tissues in the cervical spine capable of transmit-

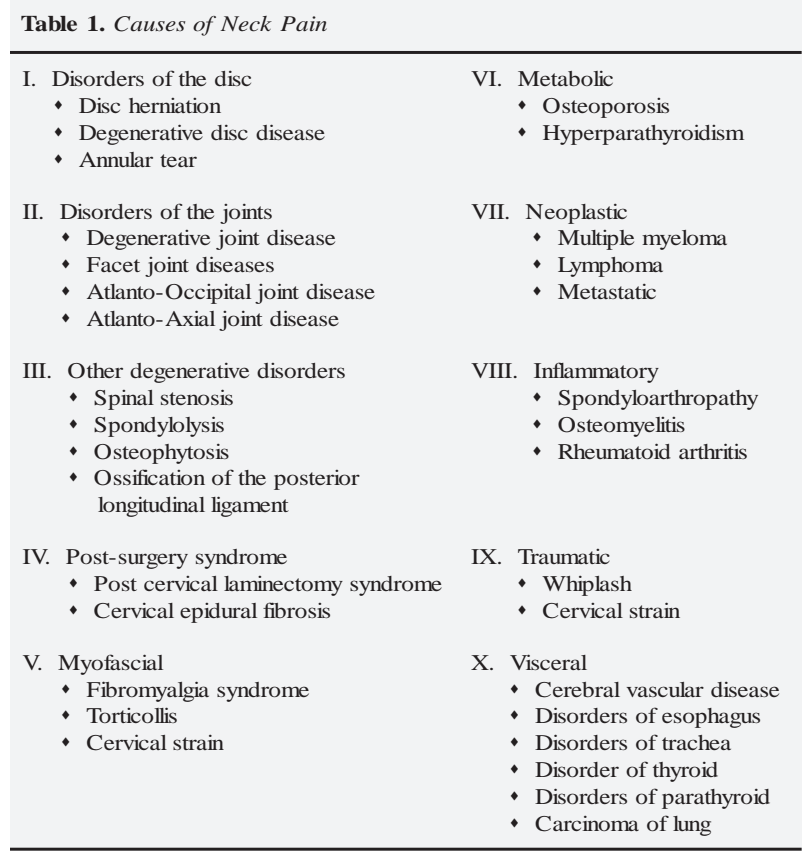

ting pain include muscles, ligaments, fascia, disc, nerve root dura, and facet joints. The nucleus, ligamentum flavum, and vertebral body are considered as non-pain sensitive(43). Degenerative cascade of lumbar spine described by Kirkaldy-Willis et al (50) with three phases has been applied to the cervical spine with redefinition with four phases: degeneration-dysfunction, discogenic, spondylosis, and stabilization(51). These phases represent a conceptual view and cervical degeneration as a spectrum of disease, which is most often multilevel and starts in early life(Fig.1). Cervical spondylosis is a term utilized to describe the cervical spine characterized by narrowing of the intervertebral foramina by cartilaginous or osseous bars and osteophytes stemming from the intervertebral discs and facet joints which encroach upon the spinal nerves and may cause nerve root compression, intrathecal fibrosis, and axonal degeneration(52-60). However, neck pain poorly correlates with cervical spondylosis. It is also hypothesized that cervical spinal pain commonly originates from multiple structures as changes in each member of the three joint complex will result in changes of others. It has been shown that the facet joint, intervertebral disc, interspinous ligament, and supraspinous ligament contain free 
nerve endings(44-49). The pathophysiologic mechanisms by which neck pain is produced are: 1) Direct external neural compression of the cervical spinal cord or cervical nerve roots, 2) Central or intraneural cord pressure, 3) Derangement of the cervical disc(s), 4) Derangement of facet joint(s), 5) Intrinsic osseous or ligamentous lesion, and 6) Abnormal motion or instability of the articulating cervical spine motion segments. It was also postulated that in addition to the potential anatomical origin of chronic neck pain, some evidence exists as to the central sensitization as a relevant mechanism(41). A variety of causes responsible for chronic neck pain are listed in Table 1.

\section{Disorders of the Disc}

The pathogenesis of discogenic neck pain is based on either acute distortion of the structures as a result of trauma or degenerative changes occurring over a long-term basis. Even though degeneration of the cervical disc structures is a normal consequence of the aging process, it undoubtedly plays a significant role in the production of neck pain, nerve root pathology, and spinal cord compression(52-60). It is stated that disc degeneration in the cervical spine begins as early as age 14 , with a prevalence of $10 \%$ at age 20 and continues through the age of 65, approaching a $95 \%$ prevalence $(1,52-54)$. Buckwalter et al(53) described the development of disc degeneration as a cascading process that is the result of multiple trauma, biochemical destabilization, and abnormal stresses, resulting in changes of the disc height, physical narrowing of the intervertebral disc space, development of degenerative spondylotic osteophyte formation of the endplate, and, finally, loss of normal intervertebral motion segment. The description of disc herniation in the lumbar region was initially made by Mixter and Barr in 1934(61). Cervical disc herniation with radiculopathy was described by Semmes and Murphy in 1943(62). Subsequently, Spurling and Scoville(63) and Michelson and Mixter(64) published additional reports of cervical disc herniation in 1944. The most common areas of disc herniation are C5-6 and C6-7 with C6 and C7 radiculopathy(65-70). The annual incidence of cervical radiculopathy from all causes has been described to be 85 per 100,000 population (67). Crock(71) described the irritation and stretch phenomena of nerve fibers with annular tear. He also defined the pathologic entity of internal disc destruction (IDD) in lumbar spine(72). However, this model cannot be applied to the cervical spine. Consequently, cervical discogenic syndrome is thought to result from degeneration of the disc, most often in association with superimposed trauma(73-77). The progressive cascading deterioration with its irritative effect on small or large neural fibers, results in either central, radicular, or myelopathic conditions(78). The location and type of painful symptoms depends on anatomic origin in the posterior primary nerve root ramus of these annular nerve fibers, which may present as axial or radicular pain $(44,45)$. Bogduk and Aprill(79) in a study of 56 patients with chronic neck pain of traumatic origin, utilizing provocative and analgesic discography, showed prevalence of cervical discogenic pain without involvement of facet joints in $20 \%$ of patients while disc and facet joints were shown to be causative in $41 \%$ of the patients, thus incriminating the disc in $61 \%$ of the patients.

\section{Disorders of the Joints}

The first proclamation of facet joints as a potential source of low back pain was by Goldthwait in 1911(80). In contrast, the cervical facet joints have attracted relatively little attention as possible sources of neck pain and referred pain in the upper extremities. Bogduk and Marsland(81, 82) studied the role of cervical facet joints in causation of idiopathic neck pain by utilizing diagnostic cervical medial branch blocks and facet joint injections and reported two major groups of patients, those with neck pain and headache stemming from the $\mathrm{C} 2-3$ joints and those with neck pain and shoulder pain stemming from the C5-6 joints. Dwyer et al(83) mapped out specific locations of referred neck pain by performing facet joint injections in normal volunteers, while Aprill et al(84) confirmed the accuracy of the pain chart reported by them earlier following anesthesia of the medial branches of the dorsal rami above and below the symptomatic joint. Dreyfuss et al(85) showed that Atlanto-Occipital (C0-C1) and Atlanto-Axial (C1-C2) facet joints could be potential sources of occipital and upper cervical pain by injecting contrast medium in normal volunteers. Fukui et al(48) also studied the referred pain distribution of each facet joint from $\mathrm{C} 0-1$ to $\mathrm{C} 7-\mathrm{T} 1$ in a large number of patients with suspected facet joint mediated pain. Bogduk and Aprill(79) estimated that the prevalence of facet joint mediated pain is $64 \%$ in patients with chronic post-traumatic neck pain. Two subsequent well controlled studies using either comparative local anesthetic blocks or placebo-controlled triple diagnostic blocks showed the prevalence of cervical facet joint mediated pain as $54 \%$ and $60 \%$ in patients with chronic neck pain after whiplash $(86$, 87). In addition, C2-3 facet joint was implicated as source of headache in $50 \%$ and $53 \%$ of patients. While the prevalence of facet joint mediated chronic neck pain with histories other than whiplash has not been determined, it is expected to be similar(22).

\section{Myofascial Syndromes}

Myofascial pain syndrome, which is a regional muscle pain disorder accompanied by trigger points appears to be a common phenomenon in the cervical spine(88-90). In the head and neck region, it is believed that myofascial pain 
syndrome can manifest not only with mechanical symptoms in the neck, but as a headache, tinnitus, shoulder pain, temporomandibular joint pain, eye symptoms, and torticollis(88-90). However, there is absolutely no epidemiological data on the prevalence of myofascial pain in the neck $(91,92)$. The role of trigger points and myofascial pain in whiplash injuries was explored by Barnsley et al(91). They believed that the theory of trigger points lacks demonstrated internal validity. Formal studies also have shown that myofascial experts have difficulty in agreeing as to the presence of a trigger point, which is the cardinal future of regional myofascial pain syndromes(93). Bogduk and Simons(94) also described that several of the classic trigger points of the neck muscles lack the major diagnostic futures of a trigger point. They noted that the tenderness was present but not the palpable band and the twitch response, thus they do not satisfy the formal definition of a trigger point. They also noted that topographically, the trigger points of the neck overlie the cervical facet joints, and they reported that pain patterns of cervical trigger points are identical to those of referred pain from the facet joints. Hence, even though the most common diagnosis for neck pain and headaches is acute or chronic cervical strain, the scientific evidence for chronic neck pain of muscle origin is not overwhelming (95).

\section{Other Causes}

Various other conditions include conditions of neurogenic etiology, instability, metabolic, inflammatory, congenital, and viscerogenic. Neurogenic conditions imply that the primary pathology is a problem of the central or peripheral neurological tissue, either intrinsic or extrinsic. Intrinsic neurogenic conditions include primary neoplasmic nerve conditions, inflammatory conditions such as Herpes Zoster and demyelinated conditions of the neural elements such as multiple sclerosis. In contrast, extrinsic nerve conditions including degenerative or congenital spinal stenosis, entrapment neuropathies, and brachial plexus pathology. Instability with excessive vertebral motion secondary to trauma to the cervical spine or trauma to soft tissues results in disruption of the stabilizing structures such as the longitudinal, supraspinous, and interspinous ligaments, as well as ligamentum flavum and the facet joint capsule. Metabolic conditions include osteoporosis and hyperparathyroidism. Inflammatory conditions of cervical spine include osteoarthritis, rheumatoid arthritis, spondyloarthropathy, and osteomyelitis. Viscerogenic causes of cervical spine include disorders involving the esophagus, trachea, thyroid, parathyroid, glandular tissue, carcinoma of the lung, and cerebral vascular insufficiency.

In addition, mechanical stimulation can trigger an inflammatory response mediated by a growing number of known chemical substances. These chemical substances are grouped into neurogenic and non-neurogenic mediators. These mediators initiate, enhance, and perpetuate the inflammatory response. By stimulating specific properties, these mediators alter the mechanical properties of the spine and perpetuate the degenerating aging spiral.

\section{NEURALBLOCKADE}

The first report of neural blockade in the cervical spine was of Kappis(96) in 1912, who described posterior approaches to the lower seven cervical nerves for the purposes of cervical and brachial plexus block to treat acute and chronic pain with Procaine. Wertheim and Rovenstine(97) devised and described a technique of suprascapular nerve block as a treatment of intractable shoulder pain, such as subacromial bursitis in 1941. A nerve block service was established by Rovenstine in 1936(98). By the 1950's, many anesthesiology-based pain relief clinics, using nerve blocks as the primary treatment or diagnostic method, were established in the United States and the United Kingdom(99). The concept of myofascial pain and trigger point injections was described in 1952(100).

The advent of cervical facet joint blocks and cervical epidural injections lagged behind that of lumbar facet joint blocks and lumbar epidural injections. Sluijter and Koetsvelb-Baart(23) devised a technique for blocking the cervical dorsal rami near their origin and described a percutaneous radiofrequency technique to coagulate these nerves, which was improved and then adapted by others (24). Okada(101) in 1981, introduced intra-articular cervical facet joint blocks using a lateral approach. In 1983, Dory(102) described a posterior approach based on a pillar view of the cervical facet joints. Bogduk and Marsland(81) developed cervical medial branch blocks. Subsequently, Barnsley and Bogduk(103) showed that medial branch blocks are specific for the diagnosis of cervical facet joint mediated pain. McCormick(31) described a means of entering the lateral Atlanto-Axial joint for the purpose of injecting local anesthetic and/or corticosteroid. While extensive literature on lumbar and caudal epidural injections exists, the use of epidural steroids in cervical spine injections failed to appear in the literature until 1961(32). Goebert et al(32) reported 3 cervical epidural injections in their series of 113 patients treated with injection of procaine and hydrocortisone. No further reports appeared until 1984(33). Even then, the literature on cervical epidural steroid, is limited compared to lumbar and caudal epidural steroids.

Neural blockade is an extremely popular tool for diagnostic purposes in evaluation of neck pain, even though it has not developed a definitive role in the management of chronic neck pain and associated syndromes. The postu- 
lated reasons for effectiveness and usefulness of neural blockade in patients with chronic pain are: interruption of nociceptive input, interruption of reflex mechanism of the afferent limb, interruption of self-sustaining activity of the neuron pools in the neural axis, and the concept of hyperstimulation analgesia (104). The postulated benefits of neural blockade include: pain relief which outlasts by hours, days, and sometimes weeks the pharmacologic action of either local anesthetic or other adjuvant agents. The proposed benefits of local anesthetics is based on the evidence that they cause interruption of pain-spasm cycle, interrupt the reverberating nociceptor transmission and dampen C-fiber activity $(105,106)$. Corticosteroids on the other hand. reduce inflammation by inhibiting the synthesis or release of pro-inflammatory substances(107-115). Proposed modes of action of steroids are based on their ability to stabilize membranes, inhibit neural peptide synthesis or action, block phospholipase $\mathrm{A}_{2}$ activity, and to increase the duration of suppression of neuronal discharge(107-115). In addition, physical effects include clearance of adhesions or inflammatory exudates from and around the nerve root sleeve. The intravenous administration of methyl prednisolone dramatically reduced the nerve root injury produced by epidural application of autologous nucleus pulposus in an experimental pig model, and epidural injections of betamethasone in a rat model of lumbar radiculopathy showed a significant effect on thermal hyperalgesia(114-115). Various types of nerve blocks utilized in managing chronic neck pain include facet joint blocks, epidural injections, trigger point injections, disc injections, and neurolytic blocks.

\section{Rationale}

The rationale for diagnostic neural blockade in the management of neck pain stems from the following facts: no clinical features, imaging, or neurophysiologic studies per-

Table 2. Estimated Epidemiology of Neck Pain and Related Syndromes

\begin{tabular}{lc}
\hline Discogenic pain & $41-61 \%$ \\
Facet joint mediated pain & $54-60 \%$ \\
Disc herniation & $2-10 \%$ \\
Spinal stenosis & $2-12 \%$ \\
Spondylosis & $10-20 \%$ \\
Myofascial & $5-20 \%$ \\
Medical causes & $1-5 \%$ \\
Other causes & $1-10 \%$ \\
\hline
\end{tabular}

mit the accurate diagnosis of causation of neck pain and referred pain; structural and morphological changes do not predict levels of pain or disability; the cervical facet joints have been shown capable of being a source of neck pain and referred pain in the head or upper extremity in normal volunteers; controlled studies have shown that among patients with chronic neck pain after whiplash, for which no other cause is evident, the prevalence of cervical facet joint pain is approximately $50 \%$; preliminary investigations of disc stimulation showed significant evidence of discogenic disease; and existence of cervicogenic headache originating from various structures in the neck $(7,9$, $22,43,79,81,82-87)$. It has been estimated that $85 \%$ of patients with chronic low back pain can not be given a definitive diagnosis based on traditional evaluations including history, physical examination, imaging studies, and electrophysiologic studies $(116,117)$. Even though no such literature is available for chronic neck pain, it appears that the majority of patients with chronic neck pain and associated syndromes go without a diagnosis, due to inability to identify an exact source of pain. Consequently, explanations of the pain has been based on the anatomy of the functional spine unit rather than physiology of the pain response (118). Based on the present literature, facet joint mediated pain appears to be the single most common source of chronic pain and probably the most overlooked diagnosis in medicine. Based on clinical studies and anatomical innervation, facet joints, intervertebral discs, nerve roots, atlanto-axial, and atlanto-occipital joints are considered as cardinal sources of chronic neck pain. Utilizing the alternative means of diagnosis with precision diagnostic blocks, when definitive diagnostic radiological criteria is lacking, an examiner can identify a source of pain in the majority of the patients(Table 2). Diagnostic facet joint injections, disc stimulation, atlanto-occipital injections, atlanto-axial injections, and nerve root blocks have all been described as capable of identifying the source of chronic neck pain and associated syndromes. Barnsley et al(91) considered elimination of neck pain by anesthetizing the structures suspected of being symptomatic as the most logical approach to investigate chronic neck pain.

Similarly, the rationale for therapeutic neural blockade is based on a multitude of considerations: the cardinal source of neck pain-namely facet joints, intervertebral discs, nerve roots, atlanto-axial joints, and atlanto-occipital joints-are accessible to neural blockade; correction of structural abnormalities of the cervical spine may fail to cure and at times may even worsen painful conditions; degenerative processes of the cervical spine and origin of spinal pain are an extremely complex phenomenon; and failure of a multitude of interventions to show effectiveness unequivocally. 
The specific rationale for cervical facet joint injections is based on the philosophy that, if a particular joint is determined to be the source of pain generation, long term relief can be sought by directing therapeutic interventions at that joint. In fact, long term therapeutic improvement has been reported from the anesthetic and corticosteroid injections into the facet joints or by denervation of the medial branches(20-27). The philosophy of injection of steroids into facet joints and the epidural space is based on presumption of anti-inflammatory properties of corticosteroids (119-123).

Anatomical and experimental studies of nerve root infiltration in the cervical and lumbar spine has been shown to be a valuable and reliable technique when the localization of the symptomatic level can not be assessed by any other diagnostic procedure(124 - 126). Kikuchi(125) showed that when cervical nerve root infiltration was performed on dogs and human cadavers, the spread of contrast material was noted under the epiradicular sheath. He concluded that selective infiltration of each nerve root with the contrast material and/or local anesthetic is possible by the existence of the epiradicular sheath. The indications for diagnostic nerve root or epidural blocks are limited to: indeterminate radiographic findings; lack of correlation of radiographic findings with clinical symptomatology; and radio-

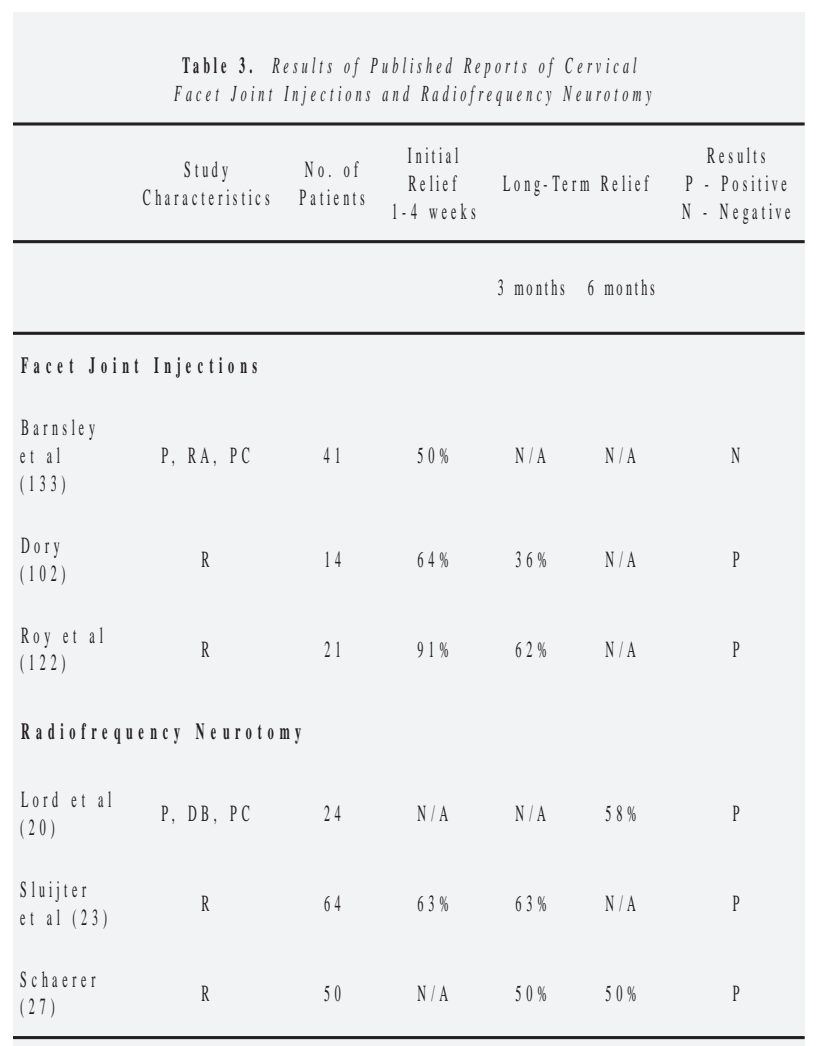

$P=$ Prospective, $P C=$ Placebo Controlled, $R=$ Retrospective, $R A=$ Randomized, $D B=$ Double Blind graphic suggestion of multilevel involvement. Similarly, rationale for intradiscal injection of steroids is based upon its usefulness as a conservative alternative to extensive surgical intervention (127). The rationale for adhesiolysis and injection of hypertonic saline into the epidural space stems from the fact that continued pain after cervical laminectomy and fusion is a common phenomenon even though exact or approximate incidence of epidural fibrosis has not been studied and established in the cervical spine (128).

\section{Clinical Effectiveness}

The number of available randomized clinical trials (RCT's) are very few in the cervical spine literature. In this evaluation of the efficacy of neural blockade in the management of chronic pain of cervical origin, both well controlled, as well as quality uncontrolled studies, are considered with an emphasis on well controlled studies.

Facet Joint Blocks: Even though diagnostic blocks are the only means available of identifying facet joint mediated pain, caution must be exercised in interpretation of the results due to an inordinately high false positive rate of single blocks(129-132). Anatomic studies have shown that the C3-4 to C7-T1 facet joints are supplied by the medial branches of the cervical dorsal rami with each joint receiving supply from the medial branches above and below its location(44). In contrast, C2-3 joint is innervated by the third occipital nerve as it crosses the back of the joint (82). The success associated with facet joint injections, medial branch blocks, and radiofrequency thermoneurolysis has varied widely(20, 23-27, 31, 101, 102, 120-123, 133-135). Similar to cervical facet joint blocks, atlanto-occipital and atlanto-axial joint injections have been reported with varying success $(29,30)$. However, the lateral Atlanto-Axial joint does not lend itself to radiofrequency thermoneurolysis, as this joint is not supplied by medial branches of the cervical dorsal rami, but receives articular branches from the $\mathrm{C} 2$ ventral ramus. Hence, for therapeutic purposes, radiofrequency of $\mathrm{C} 2$ ganglion may be considered.

The only controlled trial of intra-articular injections of steroids into the cervical facet joints illustrated no particular benefit. Barnsley et al (133) studied 41 patients with neck pain due to whiplash injury in a randomized double blind investigation. After a symptomatic cervical facet joint was identified, a therapeutic trial of intra-articular local anesthetic, or local anesthetic with steroid was injected into 41 of 42 patients. The authors showed that the time to return to $50 \%$ of baseline pain was three days in the steroid group and 3.5 days in the local anesthetic group. They also reported that less than half of the patients reported relief of pain for more than one week, and less than 1 in 5 patients reported relief for more than one month, irrespective of the 
Table 4. Results of Published Reports on Cervical Epidural Injections

\begin{tabular}{|c|c|c|c|c|c|}
\hline & $\begin{array}{l}\text { No. of } \\
\text { Patients }\end{array}$ & $\begin{array}{l}\text { No. of } \\
\text { Injections }\end{array}$ & $\begin{array}{c}\text { Initial } \\
\text { Relief } \\
1-4 \\
\text { weeks }\end{array}$ & $\begin{array}{l}\text { Long-Term } \\
\text { Relief } \\
6 \text { months }\end{array}$ & $\begin{array}{c}\text { Results } \\
\text { P - Positive } \\
\text { N - Negative }\end{array}$ \\
\hline Stav et al (39) & 52 & $1-3$ & $76 \%$ & $68 \%$ & $\mathrm{P}$ \\
\hline $\begin{array}{l}\text { Pawl et al } \\
\text { (140) }\end{array}$ & 36 & -- & $80 \%$ & -- & $\mathrm{P}$ \\
\hline $\begin{array}{l}\text { Bush \& Hillier } \\
\text { (141) }\end{array}$ & 68 & $1-3$ & -- & $93 \%$ & $P$ \\
\hline $\begin{array}{l}\text { Cicala et al } \\
(40)\end{array}$ & 58 & -- & $70 \%$ & $49 \%$ & $\mathrm{P}$ \\
\hline $\begin{array}{l}\text { Warfield et al } \\
\text { (37) }\end{array}$ & 16 & $1-3$ & $70 \%$ & $25 \%$ & $\mathrm{P}$ \\
\hline
\end{tabular}

treatment received. This led to the conclusion that intraarticular injection of steroid was not an effective treatment for cervical facet joint pain associated with whiplash injuries. They also cautioned that the results of this study should not be extrapolated to the treatment of patients with cervical facet joint pain from other causes as response to intra-articular steroid injections is not known in cervical facet joint mediated pain of spontaneous origin.

A number of uncontrolled observations have suggested that intra-articular injection of corticosteroids may be useful in the treatment of pain of the cervical facet joints(101, 102, 120-123). Dory(102) studied the effectiveness of injection of corticosteroid into cervical facet joints in 14 patients and reported that 9 of the 14 patients experienced significant initial relief, whereas, 8 of them experienced relief for one month, however; only 5 patients experienced 3 months of relief. In a similar study Hove and Glydensted(121) reported their experience with cervical analgesic facet joint arthrography in 11 patients with 9 of these patients having undergone previous surgical intervention(s). They reported a positive pain test in $60 \%$ of the patients, with duration of relief lasting only a few hours to a few days. Roy et al (122) studied 21 patients with 39 facet joint infiltrations with corticosteroids, with 22 intra-articular and 17 periarticular injections. They reported relief in $91 \%$ of the patients ranging from one week to 12 months. Symptom recurrence was seen in $71 \%$ of patients with complete response and $62 \%$ of these with partial relief.

An alternate treatment for facet joint mediated pain is blockade of the medial branches at the level of the involved joint and below. The interruption of the medial branch has been addressed in numerous ways, including local anesthetic blockade, surgery, radiofrequency lesioning, and cryoanalgesia. The role of medial branch blocks with local anesthetic is considered superior to intra-articular comparative local anesthetic blocks. However, for therapeutic purposes, the literature is sparse and there are no controlled studies. The only study in the literature, which was by Barnsley and Bogduk (103), studied 16 consecutive patients with chronic neck pain from motor vehicle accidents, reporting complete or definite relief of their pain in 11 patients. Multiple investigators have studied the efficacy of radiofrequency denervation of cervical medial branches with variable results. Percutaneous radiofrequency neurotomy has been considered a procedure which offers temporary relief of pain by denaturing the nerves that innervate the painful joint. However, it is known that the pain returns when the axons regenerate. Fortunately, relief can be reinstated by repeating the procedure. Table 3 summarizes the effectiveness of facet joint blocks and neurolysis in the cervical spine.

In a prospective, double blind, placebo controlled study of percutaneous radiofrequency neurotomy for chronic cervical facet joint mediated pain secondary to whiplash injuries in a group of 24 patients with a 34 month median duration of pain emanating from one or more cervical facet joints, Lord et al(20) reported that the median time that elapsed before the pain returned to at least $50 \%$ of the preoperative level was 263 days in the active-treatment group and 8 days in the control group $(\mathrm{p}=0.04)$. They also reported that at 27 weeks, 7 patients in the active-treatment group and 1 patient in the control group were free of pain. The literature contains multiple reports of percutaneous radiofrequency neurotomy in the literature. However, these studies have been criticized because they were hampered by poor selection of patients, inaccurate techniques, poor outcome measures, and lack of controls (20, 23-27, 136, 137). Schaerer(27) studied 50 patients with chronic neck pain with an average duration of 24 months. He reported good pain relief in $50 \%$ of the patients. fair pain relief in $18 \%$, and poor pain relief in $28 \%$ of the patients. However, the duration of pain relief was not described in this study. Sluijter et al(23) studied the effectiveness of percutaneous facet denervation in 64 patients with cervical pain syndromes and reported good results in $41 \%$ of the patients with improvement of $70-100 \%$, fair results in $22 \%$ of the patient with improvement of 40 to $70 \%$ improvement, and poor results in $37 \%$ of the patients. They also reported that the pain relief was better at the lower cervical facet joint levels below C4-5 compared to the upper levels above C4-5. There was no long term follow up of patients in this study even though initial results were encouraging.

Similar to denervation of the medial branches, radiofrequency therapy of the cervical dorsal root ganglion was 
also studied. In a prospective investigation, Van Kleef, et al(138) studied 20 consecutive patients with intractable chronic neck pain who were treated with radiofrequency lesion of the dorsal root ganglion at C4, C5, or C6. They reported pain relief in $75 \%$ of the patients after 3 months and in $50 \%$ of the patient after 6 months. They also reported good results in another study by producing radiofrequency lesions adjacent to dorsal root ganglion for cervical brachial pain (139).

Epidural injections: Two approaches available to access the epidural space in the cervical spine are interlaminar approach generally known as cervical epidural, and transforaminal approach also known as selective nerve root block or selective epidural injection. The spread of the solution in interlaminar injections (cervical epidural) is uncontrollable, diffuse, and localization of injection to a specific level is unreliable. Presumably, these disadvantages are eliminated with transforaminal injections with improvement of the target specificity of the injection, thus delivering the injectate to the cardinal site of pathology. While several studies (Table 4) describe the effectiveness of cervical epidurals in the management of chronic spinal pain only one describes transforaminal epidural injections in the cervical spine $(33-40,140,141)$.

Stav et al(39) studied 52 patients with chronic resistant cervical brachialgia in a randomized controlled study. They divided patients into two groups with 25 patients in Group A who were treated with cervical epidural steroid and lidocaine injections, and 17 patients in Group B who were treated with steroid and lidocaine injections into the posterior neck muscles. One to 3 injections were administered at 2 week intervals according to the clinical response. All patients continued with their various pre-study treatments: non-steroidal anti-inflammatory drugs, non-opioid analgesics, and physiotherapy. One week after the last injection, very good and good pain relief was reported in $76 \%$ of the patients in Group A, as compared to $36 \%$ of the patients in Group B. At one year $68 \%$ of the Group A patients continued to have very good and good pain relief, whereas only $12 \%$ of Group B patients reported similar pain relief, with statistically significant differences. Stav et al (39) also reported that they failed to achieve significant improvement of tendon reflexes or of sensory loss in both groups, but the increase in the range of motion, the percentage of the patients who were able to decrease their daily dose of analgesics, and recovery of the capacity for work was significantly better in Group A.

Pawl et al (140) in a retrospective evaluation reviewed the records to 247 patients treated with epidural injections be- tween 1981 and 1982 with a minimum of 18-months followup period. Among these, a total of 103 patients with cervical syndromes were seen and treated with epidural steroid injections. Thirty-five of those patients ultimately required surgical intervention. Of the 68 patients who were not considered for surgery or refused surgery, only 36 were considered to have typical radicular symptoms. Twentynine of 36 patients or $80 \%$, indicated that the relief of pain from the epidural steroid injection was $50 \%$ or more. Pawl et al (140) concluded that $50 \%$ of the patients with cervical radicular syndromes were able to avoid surgery with the help of epidural injections. The shortcomings of this investigation include its retrospective nature, combination of lumbar and cervical discogenic spondylosis patients, lack of long-term follow-up, exclusion of the patients undergoing surgical interventions in calculation of the successful group, and finally, lack of outcome measures.

Bush and Hillier (141) described the response of 68 patients to cervical epidural steroids injections with neurologic deficits of two months duration and an abnormal MRI in a prospective evaluation. They initially utilized a nonfluoroscopically guided lateral approach at C7. If significant improvement was not seen after the first injection, a repeat injection was performed transforaminally with fluoroscopic guidance within one month. Similarly, a third injection was performed if needed in the same manner as the second injection. An average of 2.5 injections per patient was required for adequate pain control. Overall, 93\% of the patients reported pain relief lasting 7 months. The criticisms of this study include lack of randomization and outcome parameters.

Various other evaluations have shown success rates with cervical epidural injections varying from $64 \%-79 \%$ for less than 3 months, 50\%-68\% for 3-6 months, and 25\%-68\% for over 6 months (34-38).

The role of adhesiolysis and epidural injection of hypertonic saline was studied by Racz, et al (128) for pain control for spinal pain at all levels. In this retrospective study, they reported 30 cervical epidural catheter placements and injections with significant relief on discharge in $87 \%$ of the patients; with relief lasting for less than 1 month in $77 \%$ of the patients; 1 to 3 months in $39 \%$ of the patients; 4 to 6 months in $12 \%$ of the patients; and greater than 6 months in $8 \%$ of the patients. However, these results have not been reproduced. The procedure described by Racz et al (128) includes adhesiolysis, injection of local anesthetic and steroid, followed by hypertonic saline neurolysis on day one with repeat injections of local anesthetic and hypertonic saline on day two and day three. In another retrospective analysis, it was shown that modification of Racz 
technique of adhesiolysis and neurolysis to be completed in one day, demonstrated no significant differences either with regards to the quality or duration of relief in the treatment of chronic low back pain compared to either a 2 day or 3 day procedure, but showed significant reductions in the cost(142).

\section{Other Blocks}

Numerous types of blocks other than facet joint blocks and epidural injections have been used in the management of chronic cervical spine pain and include occipital nerve blocks, paravertebral somatic nerve blocks, trigger point injections, sympathetic blocks, intradiscal injections, and injection of proliferant solutions. While most of these techniques have been described in the literature, the efficacy of these techniques in managing chronic spinal pain of cervical origin has not been studied. While diagnosis of myofascial pain syndrome and treatment of this syndrome with trigger point injections is extensively used, evaluation of the long-term, clinical efficacy of various therapies for myofascial pain syndrome suffered as a result of inadequate objective measures of severity and the absence of pre and post treatment assessments with control groups (89). Dry needling, as well as injection of various local anesthetics, steroids, and other substances has been reported in managing of chronic neck pain $(89,143-145)$. Even though Lewit(143) reported that when 312 pain sites were needled, an immediate analgesic effect was obtained in $87 \%$ of the cases and permanent relief was achieved at 92 pain sites, the use of saline or local anesthetic appears to be more effective than dry needling or placebo with local anesthetic being superior to saline $(144,145)$.

Prolotherapy consists of local injection into the painful and tender areas, usually ligamentous structures, of a proliferant solution with a multitude of combinations(146149). The effectiveness of prolotherapy is based on two diverse explanations: strengthening of ligamentous structures, or neurolysis by proliferant agents(146-149). While well controlled studies were published in managing chronic low back pain, no such studies exist in management of neck pain or cervicogenic headache. However, in uncontrolled reports Hackett et al(147) reported good to excellent results in $90 \%$ of 82 consecutive patients treated with prolotherapy in the management of chronic pain syndromes of cervical spine origin. Similarly, Kayfetz et al(148) reported excellent results in $63 \%$, and good results in $16 \%$ of the 206 traumatic headache patients. However, in 56 patient with non-traumatic headaches, only $29 \%$ experienced excellent results, with an additional $18 \%$ experiencing good results.

Intervertebral discs are considered as one of the causes of painful conditions emanating from the cervical spine. The use of cervical discography as a diagnostic and prognostic tool was introduced in 1957 by Smith and Nichols(150), and it remained the center of controversy ever since. Controversy stems from the difficulty of interpreting the clinical significance of age related cervical degenerative changes and also from the lack of objective precision with which the provocative pain response is interpretable, even though there are numerous favorable reports of discography(151-159). Recently, Schellhas, et al(158) in a study of 10 patients with chronic neck pain, found 15 concordantly painful discs and demonstrated a lack of correlation between painful discs and MRI findings or annular tears. In addition, Boden et al (160) demonstrated that there was a $19 \%$ incidence of signal changes in the cervical discs associated with slight to moderate disc protrusions in asymptomatic patients. Anterior cervical fusion studies which included discography to determine fusion levels and surgical success showed variable success rates from $70 \%$ $90 \%(161,162)$.

Wilkinson and Schuman(127) evaluated the role of intradiscal steroids in the treatment of lumbar and cervical disc problems. This study included 18 injections in 13 patients with cervical disc problems. None of these patients underwent previous surgery, and all received injections of $80 \mathrm{mg}$ of Depo-Medrol ${ }^{\circledR}$. The results showed that injections for predominately discogenic pain yielded good responses in $75 \%$ of the patients. Of the ten injections for predominately radicular pain with no significant objective neurological loss, 50\% showed significant improvement. They reported that $20 \%$ of the patients had lasting good results.

Van Kleef and Sluijter(163) treated 27 patients with long standing post-traumatic neck pain with discography and radiofrequency lesioning. They reported more than 50\% improvement lasting for 3-6 months in 56\% of patients.

\section{Complications}

Incidences of reported complications relating to cervical neural blockade are few and usually minor. However, compared to lumbar neural blockade, cervical neural blockade presents with more complications, both with frequency and risk. Total spinal block following intra-articular facet joint injections has been reported occasionally $(164,165)$. Further, with facet joint injections, the phrenic nerve may be compromised, especially if a large volume of local anesthetic is employed while blocking $\mathrm{C} 3 / 4, \mathrm{C} 4 / 5$, or $\mathrm{C} 5 / 6$ joints. Disequilibrium also has been described rather frequently, though transient following third occipital nerve block (166). Complications associated with cervical epidural injections include dural puncture, hypotension, weakness, paralysis, nausea, vomiting, bloating, dyspnea, respiratory insuffi- 
ciency, stiffness, facial flushing, fever, nerve root injury, epidural hematoma, and complications related to administration of steroids (33-35, 40, 167-169). Of all the complications, the most feared complication of performing an epidural injection in the cervical region is direct trauma to the spinal cord by the needle and/or injectate. Bromage (170) mentioned three possible cases of direct trauma to the spinal cord following thoracic epidural injections. Bromage and Benumof (171) published a case of paraplegia that occurred after intracord injection when epidural anesthesia was attempted with the patient under general anesthesia. Hodges et al (172) reported two case reports of cervical epidural steroid injection with intrinsic spinal cord damage. Epidural hematoma is a rare but possibly catastrophic complication of epidural injection in the cervical spine. It is more common in patients who have prolonged bleeding times and those over 50 years of age. Williams et al (167) reported a case of acute paraplegia secondary to epidural hematoma following a 7th cervical epidural injection in a patient on long-term indomethacin therapy, necessitating surgical decompression. In addition, anterior spinal artery thrombosis has also been associated with acute flexion of the neck in patients with cervical spondylosis. Waldman (174) reported dural puncture in $0.25 \%$ of 790 cervical epidural injections.

Bromage and Benumof (171) described that accidental injury to the spinal cord during attempted epidural anesthesia is avoidable by observing the three interrelated technical precautions: Assume that any report of lancinating pain during epidural puncture may be caused by mechanical stimulation of the spinal root or the cord itself and therefore, is a clear signal to halt the advance of the epidural needle immediately; Perform the puncture below the termination point of the spinal cord, whenever practical and medically appropriate, though this is not practical for cervical or thoracic epidurals; and When indications do exist for punctures above the termination of the cord, the procedure should be performed with all do care by clinically competent anesthesiologists and in an awake, responsive patient in all but rare circumstances.

Derby (175) expressed his view that a cervical epidural injection rarely should be performed above C7/T1. Clinical rationale for this contention is based on results from crosssectional cadaver studies and magnetic resonance imaging, revealing 1 to $2 \mathrm{~mm}$ of fat, which is visualized in the dorsal epidural space at the C7/T1 interspace, which is rarely found in the level above and narrowing of the epidural space above C7/T1 levels. Derby (175) also noted that the needles bevel may press the ligamentum flavum against the dura, at the moment when the epidural needle is on the verge of penetrating the ligamentum flavum, which in turn may become indented to press directly against the spinal cord. However, this situation may be aggravated further by the existence of an anterior disc protrusion or herniation, displacing the spinal cord posteriorly $(172,175)$. Manchikanti (176), commenting on the report of Hodges et al (172) contended that cervical selective nerve root block or selective epidural injection appears to be much more safe and benign in addition to being more accurate with delivery of the injectate to the cardinal site of pathology. In fact, Slipman et al (177) prospectively studied mechanical stimulation of cervical nerve roots, $\mathrm{C} 4$ to $\mathrm{C} 8$, in 87 patients with cervical radicular symptoms who were undergoing diagnostic selective nerve root blocks; stimulation was performed in 134 cervical nerve roots, with no incidence of nerve root or cord damage.

Other worrisome complications of neural blockade of the spine are related to infection and the side effects of steroids $(168,169)$. Infection following cervical and thoracic epidural steroid injections with subsequent development of epidural abscess has been reported (177-180). Even though reports of infection are exceedingly rare following the epidural injections as well as cervical facet joint injections, it has been reported somewhat more frequently following cervical discography. Discitis is considered a principle complication of cervical epidural discography, which reportedly occurs in $0.1 \%$ to $1 \%$ of the cases (190-192).

The side effects related to the administration of steroids are attributed to either the chemistry or pharmacology. Most commonly used agents in the United States for cervical epidural administration are methyprednisolone acetate (Depo-Medrol ${ }^{\circledR}$ ), triamcinolone diacitate (Aristocort $\AA$ ), triamcinolone acetonide (Kenalog $\AA)$, and betamethasone acetate and phosphate mixture (Celestone Soluspan () . The safety of steroids and their preservatives was demonstrated in doses administered epidurally in clinical situations in both clinical and experimental studies $(168,169,193-201)$. The major reported complications of steroid administration include suppression of pituitaryadrenal axis, hypercorticisms; Cushing's Syndrome, osteoporosis, avascular necrosis of bone, steroid myopathy, weight gain, fluid retention, and hyperglycemia $(200,202-$ 209). Other complications with steroid administration include hypertension, hypokalemia, epidural lipomatosis, retinal hemorrhage, insomnia, mood swings, psychosis, facial flushing, headache, gastrointestinal disturbances, and menstrual disturbances (206-211). The prolonged therapy with corticosteroids may result in suppression of pituitary-adrenal access, which may be slow in returning to normal even though the use of corticosteroids repeatedly for days or even a few weeks does not lead to adrenal insufficiency upon cessation of treatment. Hypothalamicpituitary-adrenal suppression has been reported infrequently following steroid administration with neural block- 


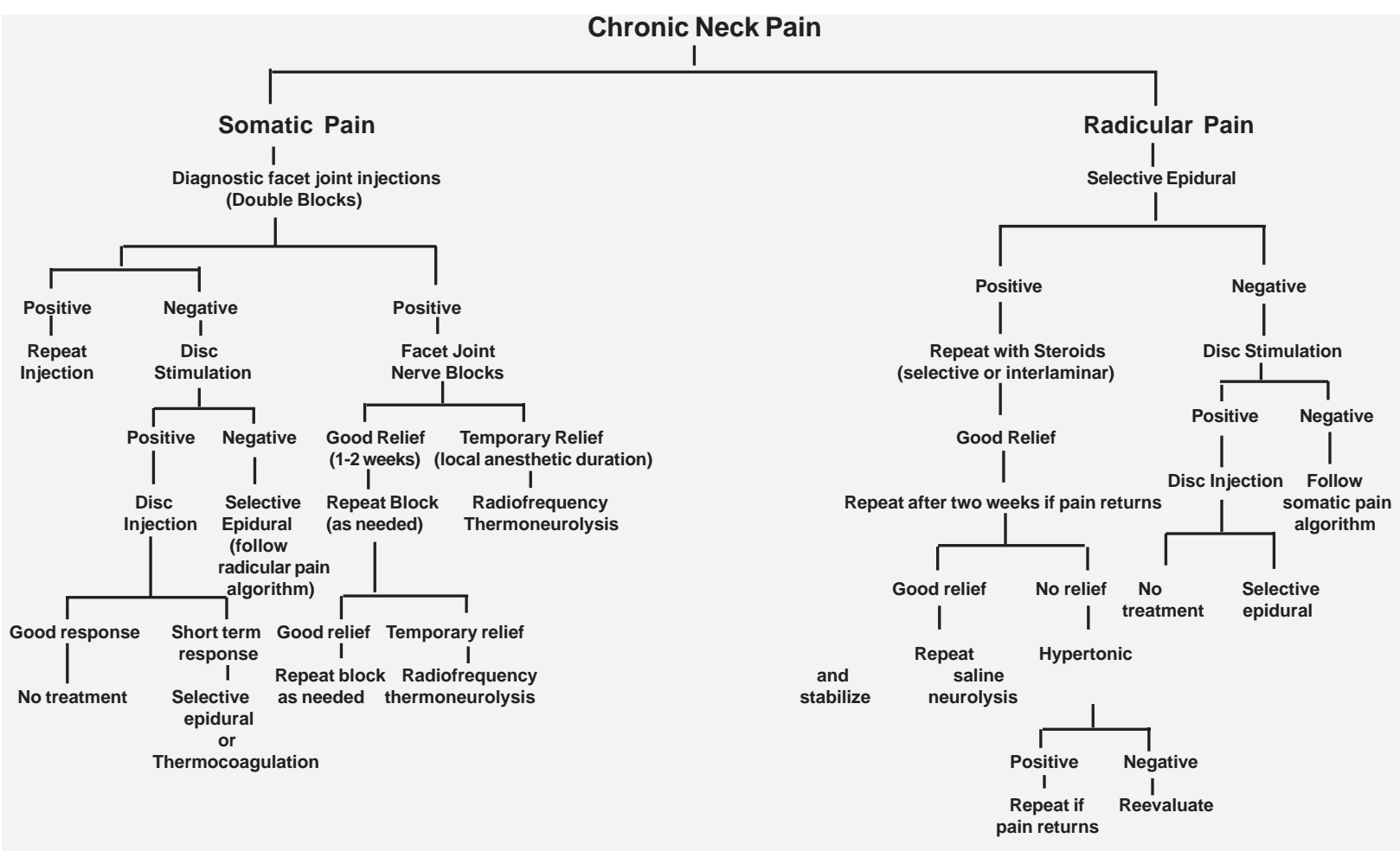

Figure 2. An algorithm for neural blockade in conservative care of chronic neck pain.

ade. Mikhail, et al $(204,205)$ in their evaluation of endogenous adrenal function during and after the administration of various types of corticosteroids, reported that adrenal suppression with $50 \mathrm{mg}$ of triamcinolone diacetate (Aristocort ${ }^{\circledR}$ ), or $9 \mathrm{mg}$ of betamethasone acetate-phosphate mixture (Celestone Soluspan ${ }^{\circledR}$ ) last only one week, in contrast to 6 weeks of adrenal suppression following the administration of triamcinolone acetonide (Kenalog ${ }^{\circledR}$ ). Table 5 illustrates the profile of commonly used steroids in neural blockade.

\begin{tabular}{|c|c|c|c|c|c|c|c|}
\hline \multirow[t]{2}{*}{ Name of Drug } & \multirow[t]{2}{*}{$\begin{array}{c}\text { Equivalent } \\
\text { Dose }\end{array}$} & \multirow[t]{2}{*}{$\begin{array}{l}\text { Epidural } \\
\text { Dose }\end{array}$} & \multirow[t]{2}{*}{$\begin{array}{l}\text { Anti-inflammatory } \\
\text { Potency }\end{array}$} & \multirow[t]{2}{*}{$\begin{array}{l}\text { Sodium } \\
\text { Retention } \\
\text { Capacity }\end{array}$} & \multicolumn{3}{|c|}{$\begin{array}{l}\text { Duration of Adrenal } \\
\text { Suppression }\end{array}$} \\
\hline & & & & & IM & $\begin{array}{l}\text { Single } \\
\text { Epidural }\end{array}$ & $\begin{array}{l}\text { Three } \\
\text { Epidurals }\end{array}$ \\
\hline Hydrocortisone & $20 \mathrm{mg}$ & $\mathrm{N} / \mathrm{A}$ & 1 & 1 & $\mathrm{~N} / \mathrm{A}$ & $N / A$ & $N / A$ \\
\hline $\begin{array}{l}\text { Depo-Methyl } \\
\text { Prednisolone } \\
\text { (Depo-Medrolo) }\end{array}$ & $4 \mathrm{mg}$ & $40.80 \mathrm{mg}$ & 5 & 0.5 & $\begin{array}{c}1.6 \\
\text { weeks }\end{array}$ & $\begin{array}{c}1.3 \\
\text { weeks }\end{array}$ & $\mathrm{N} / \mathrm{A}$ \\
\hline $\begin{array}{l}\text { Triamcinolone } \\
\text { diacetate } \\
\text { (Aristocorte) }\end{array}$ & $4 \mathrm{mg}$ & $25.50 \mathrm{mg}$ & 5 & 0 & $\begin{array}{c}1.2 \\
\text { weeks }\end{array}$ & $\begin{array}{c}1.5 \\
\text { weeks }\end{array}$ & $\mathrm{N} / \mathrm{A}$ \\
\hline $\begin{array}{l}\text { Triamcinolone } \\
\text { acetonide } \\
\text { (Kenalog@) }\end{array}$ & $4 \mathrm{mg}$ & $40.80 \mathrm{mg}$ & 5 & 0 & $\begin{array}{l}2.6 \\
\text { weeks }\end{array}$ & $\mathrm{N} / \mathrm{A}$ & $\begin{array}{c}2 \cdot 3 \\
\text { months }\end{array}$ \\
\hline $\begin{array}{l}\text { Betamethasone } \\
\text { (Celestone } \\
\text { Soluspano) }\end{array}$ & $0.6 \mathrm{mg}$ & $6 \cdot 12 \mathrm{mg}$ & 25 & 0 & $\begin{array}{c}1.2 \\
\text { weeks }\end{array}$ & $\mathrm{N} / \mathrm{A}$ & $N / A$ \\
\hline
\end{tabular}

\section{Indications}

Cervical facet joint blocks, as well as injections of the atlanto-occipital and atlanto-axial joints are performed in patients with neck pain for which no cause has been identified and whose pain pattern is similar to that of evoked normal volunteers upon stimulation of their joints. Indications for cervical facet denervation are based on shortterm but convincing relief following either facet joint injection or facet joint nerve block with two local anesthetics of variable duration. Some investigators have attempted to identify the outcome of facet joint injections in the lumbar spine and concluded that the outcome depended on the patient's biophychosocial ability of self-facilitated improvement, and suggested that somatic treatment does not work in the presence of persistent high levels of inappropriate signs $(212,213)$. While no such propositions exist in managing cervical facet joint mediated pain, Wallis, et al (21) studying the role of cervical facet denervation, reported that the pain relief achieved following radiofrequency facet denervation not only returned these patients to work but also resolved all of their psychological problems, thus questioning the extraordinary attention focused on psychological status.

The indications for cervical epidural injections either interlaminar or transforaminal include various diagnostic dilemmas and localized neural irritation, as well as post-surgical 
cervical syndromes. Ferrante et al (214) attempted to provide a clinical classification as a predictor of therapeutic outcome following the cervical epidural steroid injections. They reported that neither gender nor history of duration of pain or trauma before cervical epidural steroid injection predicted the outcome. They also reported that the injections were equally effective irrespective of the nerve root involved, while older patients with radicular pain and those without myofascial pain had better outcomes. Physical findings, abnormal sensory examination, and diminished deep tendon reflexes appeared less predictive of the therapeutic outcome than motor weakness or the presence of a positive electromyographic finding. In addition, a radiologic diagnosis of spondylosis or spinal stenosis was also associated with good pain relief after cervical epidural steroid injection. Similar to these findings, Cicala et al(40) also found that patients with cervical spondylosis had better results after cervical epidural steroid injections. Consequently, epidural injections are indicated in management of chronic neck pain with nerve root irritation secondary to herniated nucleus pulposus, degenerative disc disease, annular tear, spinal stenosis, spondylolysis, and epidural fibrosis.

Indication for disc injection is a positive stimulation and analgesic response. Evidence for this indication at the present time is equivocal. Indications for prolotherapy are met with controversy even though the controlled studies in the lumbar spine and uncontrolled studies in the cervical spine demonstrated reasonable effectiveness(146-149). It is believed that prolotherapy in indicated in refractory neck pain and headaches with multiple tender points defying the diagnosis based on findings of imaging and diagnostic neural blockade. Adhesiolysis and injection of hypertonic saline into the cervical epidural space though appears to be reasonable in management of refractory neck pain secondary to a multitude of causes, its applications remain in infancy. The steps in management of neck pain with neural blockade are described in Figure 2.

\section{Frequency and Number of Injections}

The frequency and total number of injections is a contentious issue in neural blockade of cervical spine. The limitations described in the literature are extrapolated from descriptions of lumbar epidural steroids, which are based on the authors' philosophy, passion, and preferences. These presumptions range from one injection to three injections, three injections followed by a repeat course of three injections after 3,6, or 12 month intervals, unlimited number of injections with no established parameters, an animal dose of steroid of $3 \mathrm{mg}$ per kilogram of body weight, and a life time dose equivalent to double the animal dose. None of these assumptions are based on scientific or clinically rel- evant evidence, and they also do not fit the pharmacological profile of the steroids (Table 5). The treatment plan must always be formulated around a patient's diagnosis and response to treatment with appropriate outcome parameters of improvement in quality of life. Based on the present evidence, it appears that injection therapy may be continued reasonably at intervals of 6 to 8 weeks after appropriate initial stabilization leading to either continued increase in duration between the neural blockade episodes or maintenance of a safe and reasonable time interval.

\section{Cost Effectiveness}

Evaluation of cost effectiveness of various therapeutic modalities in management of cervical spine pain has been hopelessly inadequate. It is well known that the cost of inpatient chronic pain treatment programs ranges from $\$ 17,000$ to $\$ 25,000$ whereas outpatient treatment programs range from $\$ 7,000$ to $\$ 10,000$ (215). It is also widely believed that chronic pain patients incur multiple healthcare expenditures in excess of $\$ 20,000$ annually for repetitive and basically redundant diagnostic work ups, physical therapy, psychological interventions, and drugs. MuellerSchwefe et al (216) in evaluating the cost effectiveness of intrathecal therapy for pain, estimated the cost of failed back surgery syndrome as $\$ 85,186$ for five years, with an annual cost of $\$ 17,037$ for medical management. While cost effectiveness of cervical surgical interventions has not been studied, Malter et al (217) evaluated the cost effectiveness of lumbar discectomy for the treatment of herniated intervertebral discs compared to conservative treatment and concluded that for carefully selected patients with lumbar herniated discs, surgical discectomy is a cost effective treatment at a discounted cost of $\$ 12,000$ for discectomy or $\$ 29,000$ for quality adjusted life year. While no such cost effectiveness studies are available for cervical spine with neural blockade, cost effectiveness of three types of epidural injections and adhesiolysis and hypertonic saline neurolysis, either in a heterogenous population or in post lumbar laminectomy syndrome was estimated for improvement of one year quality of life for the patient with chronic low back pain non-responsive to numerous other modalities of treatments, as $\$ 2,927$ for transforaminal steroids, $\$ 3,635$ for caudal epidural steroids, $\$ 2,028$ with non-endoscopic adhesiolysis in post lumbar laminectomy patients, and $\$ 5,564$ with non-endoscopic adhesiolysis in an heterogenous population $(142,218,219)$. Considering these reports, it appears that neural blockade, if provided appropriately, is presumably more cost effective.

\section{SUMMARY}

Chronic neck pain and related syndromes, though not as 
significant and as prevalent as low back pain, constitute a major healthcare and social problem. While numerous treatments are available in managing this problem, none of them have been proven to be efficacious and convincing on a scientific basis. Neural blockade of the cervical spine remains to be one of such treatments. Neural blockade is a diagnostic and therapeutic alternative in management of cervical pain when clinical examination, radiological evaluation, and neurophysiological evaluation fails to show an appropriate diagnosis and lesser invasive conservative measures have failed to produce resolution of symptomatology. Neural blockade in the cervical spine serves a dual function by providing not only relief of pain, but potentially providing information to help localize the underlying pain generator. The response to local anesthetic solution helps localize the site of pain, whereas a prolonged response from steroids assists to determine if the inflammation is present. Subsequently, this information helps to prove or disprove a clinical diagnosis that is formulated on the basis of the history, physical examination, and structural abnormalities as seen on imaging studies, as well as in cases where no positive findings are available.

A systematic evaluation for underlying cervical pain generator progresses from the posterior element to the neuraxis, which includes: facet joint injections or medial branch blocks for posterior column; interlaminar epidural injection or transforaminal epidural block for neuraxial column; and discography for the anterior column.

It appears that much of the confusion surrounding the utilization of neural blockade in the cervical spine results from inordinate emphasis on a biopsychosocial model as well as inappropriate selection of patients for this treatment modality (220-222). Without utilization of diagnostic blocks, the diagnosis of "nothing can be found," and the problem "is a complex biopsychosocial issue," is inappropriate and falsely justified. Wallis, et al(21) demonstrated a clear temporal relationship between pain and psychological distress, thus demonstrating the inordinate importance and over-emphasis provided to the biopsychosocial concept. It is reasonable to assume that these results should influence physicians to pursue an organic diagnosis, calling into question the present concepts about chronic pain which proclaims medical therapy alone to be ineffectual and psychological therapy to be imperative.

The available evidence with regards to the effectiveness of neural blockade in the management of the cervical spine is similar if not superior to various other modalities of treatments available in managing chronic pain originating from the cervical spine including manipulation, physical therapy, behavior management, and surgical intervention. The results show that it is unrealistic and unfair to presume that neural blockade will provide permanent relief with one treatment, whether it is epidural steroid injection, facet joint nerve block, or radiofrequency thermoneurolysis. The literature has demonstrated repeatedly, beyond any question that these modalities provide only palliation in most cases and cure in very few cases. Neural blockade is an appropriate and cost effective treatment with proper selection of patients and applications. Even though great strides have been made in radiofrequency thermoneurolysis of cervical spine, it is mandated that further meticulously controlled randomized studies be conducted to prove the unequivocal rationale and effectiveness of other treatment modalities in managing chronic cervical pain syndromes. As our understanding of the complexities of chronic pain evolves, it behooves us to synthesize and integrate knowledge, to understand that the language of pain is subjective, but the correlates are physiologically and anatomically objective.

\section{ACKNOWLEDGMENTS}

The author wishes to thank Michelle Burkeen for her dedication and patience in preparation of this manuscript; William L Wade (Professor of English), and Bert Fellows for reviewing the manuscript.

\section{REFERENCES}

1. Lawrence JS: Disc degeneration: its frequency in relationship to symptoms. Annals Rheum Dis 1969;28:121-137.

2. Gore DR, Sepic SB, Gardner GM, et al: Neck pain: a long term follow-up of 205 patients. Spine 1987;12:1-5.

3. Bovim G, Schrader H, Sand T: Neck pain in the general population. Spine 1994;19:1307-1309.

4. Spitzer WO, Skovron ML, Salmi LR, et al: Scientific monography of the Quebec Task Force on Whiplash-Associated Disorders: redefining "whiplash" and it management. Spine 1995;20 (Suppl):1-73.

5. Pfaffenrath V, Kaube H: Diagnostics of cervicogenic headache. Funct Neurol 1990;5:159164.

6. Nilsson. N: The prevalence of cervicogenic headache in a random population sample of 20-59 year olds. Spine 1995;20:1884-1888.

7. Lord SM, Barnsley L, Wallis BJ, et al: Third occipital nerve headache. A prevalence study. $J$ Neurol Neuro-Surg Psychiatry 1994;57:1187-1190.

8. Davis H: Increasing rates of cervical and lumbar spine surgery in the United States, 1979-1990. Spine 1994;19:1117-1124.

9. Rasmussen BK, Jensen R, Schroll M, et al: Epide- 
miology of headache in a general population - a prevalence study. J Clin Epidemiol 1991;44:11471157.

10. Hurwitz DC, Aker PD, Adams AH, et al: Manipulation and mobilization of the cervical spine. Spine 1996;21:1746-1760.

11. Saal JS, Saal JA, Yurth EF: Nonoperative management of herniated cervical intervertebral disc with radiculopathy. Spine 1996;21:1877-1883.

12. Aldrich F: Posterolateral microdiscectomy for cervical monoradiculopathy caused by posterolateral soft cervical disc sequestration. J Neurosurg 1990;72:370-377.

13. DePalma AF, Rothman RH, Levitt RL, et al: The natural history of severe cervical disc degeneration. Acta Orthop Scand 1972;43:392-396.

14. Blondi C, Moroni A, Catagalli S, et al: Surgical treatment of cervical HNP of 51 cases. Chir Degli Org di Mov 1990;75:311-314.

15. Gore DR, Sepic SB: Anterior cervical fusion for degenerated or protruded discs. A review of one hundred forty-six patients. Spine 1984;9:667-671.

16. Herkowitz H, Kurz LT, Overholt DP: Surgical management of cervical soft disc herniation: A comparison between the anterior and posterior approach. Spine 1990;15:1026-1030.

17. Koes BW, Assendelft WJJ, Heijden GJMG van der, et al: Spinal manipulation and mobilization for back and neck pain: a blinded review. $\mathrm{Br}$ Med J 1991;303:1298-1303.

18. Koes BW, Bouter LM, Mameren $\mathrm{H}$ van, et al: A blinded randomized clinical trial of manual therapy and physiotherapy for chronic back and neck complaints: Physical outcome measures. J Manipulative Physiol Ther 1992;1:16-23.

19. Whitecloud III TS: Management of radiculopathy and myelopathy by the anterior approach. In: The cervical spine. Sherk HH, Dunn EJ, Eismont FJ et al (Eds). Second Edition. J.B. Lippincot Company, St. Louis, 1989, pp. 644-658.

20. Lord SM, Barnsley L, Wallis BJ, et al: Percutaneous radio-frequency neurotomy for chronic cervical zygapophyseal-joint pain. $N$ Eng J Med 1996;335:1721-1726.

21. Wallis BJ, Lord SM, Bogduk N: Resolution of psychological distress of whiplash patients following treatment by radiofrequency neurotomy: A randomized, double-blind, placebo-controlled trial. Pain 1997;73:15-22.

22. Bogduk N: International spinal injection society guidelines for the performance of spinal injection procedures. Part 1: Zygapophyseal joint blocks. Clin J Pain 1997;13:285-302.

23. Sluijter ME, Koetsveld-Baart CC: Interruption of pain pathways in the treatment of cervical syndrome. Anaesthesia 1980;35:302-307.

24. Hildebrandt J, Argyrakis A: Percutaneous nerve block of the cervical facets - a relatively new method in the treatment of chronic headache and neck pain. Man Med 1986;2:48-52.

25. Schaerer JP: Treatment of prolonged neck pain by radiofrequency facet rhizotomy. J Neurol Orthop Med Surg 1988;9:74-76.

26. Vervest ACM, Stolker RJ: The treatment of cervical pain syndromes with radiofrequency procedures. Pain Clinic 1991;4:103-112.

27. Schaerer JP: Radiofrequency facet rhizotomy in the treatment of chronic neck and low back pain. Int Surg 1978;63:53-59.

28. Gawel MJ, Rothbart PJ: Occipital nerve blocks in the management of headache and cervical pain. Cephalalgia 1992;12:9-13.

29. Busch E, Wilson PR: Atlanto-Occipital and Atlanto-Axial injections in the treatment of headache and neck pain. Reg Anesth 1989;14:45-47.

30. Dreyfuss P, Roberts J, Dreyer S et al: AtlantoOccipital joint pain: A report of three cases and description of an intra-articular joint block technique. Reg Anesth 1994;19:344-351.

31. McCormick CC: Arthrography of the AtlantoAxial (C1-C2) joints: technique and results. $J$ Intervent Radiol 1987;2:9.

32. Goebert JW Jr, Jallo SJ, Gardner WJ, et al: Painful radiculopathy treated with epidural injections of procaine and hydrocortisone acetate: Results in 113 patients. Anesth Analg 1961;40:130-134.

33. Catchlove RFH, Braha R: The use of cervical epidural nerve blocks in the management of chronic head and neck pain. Can Anaesth Soc J 1984;31:188-191.

34. Shulman M: Treatment of neck pain with cervical epidural steroid injection. Reg Anesth 1986;11:9294.

35. Purkis IE: Cervical epidural steroids. Pain Clinic 1986;1:3-7.

36. Rowlingson JC, Kirschenbaum LP: Epidural analgesic techniques in the management of cervical pain. Anesth Analg 1986;65:938-942.

37. Warfield CA, Biber MP, Crews DA, et al: Epidural steroid injection as a treatment for cervical radiculitis. Clin J Pain 1988;4:201-204.

38. Castagnera L, Maurette P, Pointillart V, et al: Longterm results of cervical epidural steroid injection with and without morphine in chronic cervical radicular pain. Pain 1994;58:239-243.

39. Stav A, Ovadia L, Sternberg A, et al: Cervical epidural steroid injection for cervicobrachialgia. Acta Anaesthesiol Scand 1993;37:562-566. 
40. Cicala RS, Thoni K, Angel JJ: Long-term results of cervical epidural steroid injections. Clin J Pain 1989;5:143-145.

41. Sheather-Reid RB, Cohen ML: Psychophysical evidence for a neuropathic component of chronic neck pain. Pain 1998;75:341-347.

42. Riley LH, Long D: The science of whiplash. Medicine 1995;74:298-299.

43. Kuslich SD, Ulstrom CL, Michael CJ: The tissue origin of low back pain and sciatica: a report of pain response to tissue stimulation during operation on the lumbar spine using local anesthesia. Orthop Clin North Am 1991;22:181-187.

44. Bogduk N: The clinical anatomy of the cervical dorsal rami. Spine 1982;7:35-45.

45. Bogduk N, Windsor M, Ingus A: The innervation of the cervical intervertebral discs. Spine 1988;13:2-8.

46. Weinstein JN: Recent advances in neurophysiology of pain. Physical Medicine and Rehabilitation. State of the Art Reviews. Saal J (Ed). In: Neck and back pain. Philadelphia: Hanley \& Belfus, 1990:pp201-214.

47. Heller JC: The degenerative neck. Ortthop Clin North Am 1992;23:381-399.

48. Fukui S, Ohseto K, Shiotani M, et al: Referred pain distribution of the cervical zygapophyseal joints and cervical dorsal rami. Pain 1996;68:7983.

49. Kimmel DL: Innervation of spinal dura mater and dura mater of the posterior cranial fossa. Neurology 1961;10:800-809.

50. Kirkaldy-Willis WH, Wedge JH, Yong-Hing K, et al: Pathologic and pathogenesis of lumbar spondylosis and stenosis. Spine 1978;3:319-327.

51. Handel JA, Knap J, Poletti S: The structural degenerative cascade. The Cervical Spine. In: Spine Care. Diagnosis and conservative treatment. White AH, Schofferaian, JA, (Eds). Volume 1, Mosby, St. Louis. 1995:pp16-23.

52. Hirsch C, Schajowicz F, Galante J: Structural changes in the cervical spine. Acta Orth Scand 1967;109:68-72.

53. Buckwalter JA: Aging and degeneration of the human intervertebral disk. Spine 1995;20:13071314.

54. Brain WR, Northfield DW, Wilkinson M: The neurologic manifestations of cervical spondylosis. Brain 1952;75:187-225.

55. Crandall Ph, Batsdorf U: Cervical spondylotic myelopathy. J. Neurosurg 1966;25:57-66.

56. Hayashi H, Okada K, Hashimoto J: Cervical spondylotic myelopathy in the aged patient. Spine 1988;13:618-625.
57. Lees F, Turner JWA: Natural history and prognosis of cervical spondylosis. Br Med J 1963;2:16071610 .

58. Lestini WF, Wiesel SW: The pathogenesis of cervical spondylosis. Clin Orthop 1989;239:69-93.

59. Ono K, Ota H, Tada K, et al: Cervical myelopathy secondary to multiple spondylotic protrusions: a clinicopathologic study. Spine 1977;2:109-125.

60. Holt S, Yates P: Cervical spondylosis and nerve root lesions. J Bone Joint Surg (Br) 1966;48:407423.

61. Mixter WJ, Barr JS: Rupture of the intervertebral disc with involvement of the spinal canal. N Eng JMed 1934;211:210-215.

62. Semmes RE, Murphey MF: The syndrome of unilateral rupture of the sixth cervical intervertebral disc with compression of the seventh cervical nerve root. A report of four cases with symptoms simulating coronary disease. JAMA 1943;121:1209.

63. Spurling RG, Scoville WB: Lateral rupture of the cervical intervertebral discs. A common cause of shoulder and arm pain. Surg Gynecol Obstet 1944;78:350-358.

64. Michelsen JJ, Mixter WJ: Pain and disability of shoulder and arm due to herniation of the nucleus pulposus of cervical intervertebral discs. $N$ Engl JMed 1944;231:279.

65. Odom GL, Finney W, Woodhall B: Cervical disc lesions. JAMA 1958;166:23-28.

66. Lundsford LD, Bissonette DJ, Janetta PJ, et al: Anterior surgery for cervical disc disease. Part 1: treatment of lateral cervical disc herniation in 253 cases. J Neurosurg 1980;53:1-11.

67. Ahlgren BD, Frafin SR: Cervical radiculopathy. Orthop Clin North Am 1966;27:253-263.

68. Raynor R: Cervical cord compression secondary to acute disc protrusion in trauma. Spine 1977;2:39-43.

69. Rhoton AL, Henderson ED: Cervical disc disease with neural compression. Minn Med 1972;55:9981002.

70. O'Laoire S, Thomas D: Spinal cord compression due to prolapse of cervical intervertebral disc. $J$ Neurosurg 1983;59:847-853.

71. Crock HV: A reappraisal of intervertebral disc lesions. Med J Aust 1970;1:983-989.

72. Crock HV: Isolated lumbar disc resorption as a cause of nerve root canal stenosis. Clin Orthop 1976;115:109-115.

73. Davis SJ, Terisi LM, Bradley WG: Cervical spine hyperextension injuries: MR findings. Radiology 1991;180:245-251.

74. Harris JH, Yeakley JW: Hyperextension-dislocation of the cervical spine. Ligament injuries dem- 
onstrated by magnetic resonance imaging. J Bone Joint Surg Br 1992;74:567-570.

75. Ignelzi RJ: The potential role of low field MR with open design in assessing ligamentous injury in acute cervical trauma. Surg Neurol 1993;39:519529.

76. Shea M, Wittenberg RH, Edwards WT, et al: In vitro hyperextension injuries in the human cadaveric cervical spine. J Orthop Res 1992;10:911-916.

77. Taylor JR, Twomey LT: Acute injuries to cervical joints. An autopsy study of neck sprain. Spine 1993;18:1115-1122.

78. Friedenberg Z, Miller W: Degenerative disc disease of cervical spine. J Bone Joint Surg (AM) 1963;45:1171-1178.

79. Bogduk N, Aprill C: On the nature of neck pain, discography, and cervical zygapophyseal joint blocks. Pain 1993;54:213-217.

80. Goldthwait JE: The lumbosacral articulation: an explanation of many cases of lumbago, sciatica, and paraplegia. Boston Med Surg J 1911;164:365372.

81. Bogduk N, Marsland A: The cervical zygapophyseal joints as a source of neck pain. Spine 1988;13:610-617.

82. Bogduk N, Marsland A: On the concept of third occipital headache. J Neurol Neurosurg Psychiatry 1986;49:775-780.

83. Dwyer A, Aprill C, Bogduk N: Cervical zygapophyseal joint pain patterns: a study in normal volunteers. Spine 1990;15:453-457.

84. Aprill C, Dwyer A, Bogduk N: The prevalence of cervical zygapophyseal joint pain patterns II: a clinical evaluation. Spine 1990;15:458-461.

85. Dreyfuss P, Michaelsen M, Fletcher D: AtlantoOccipital and lateral Atlanto-Axial joint pain patterns. Spine 1994;19:1125-1131.

86. Barnsley L, Lord SM, Wallis BJ, et al: The prevalence of chronic cervical zygapophyseal joint pain after whiplash. Spine 1995;20:20-26.

87. Lord SM, Barnsley L, Wallis BJ, et al: Chronic cervical zygapophysial joint pain with whiplash: A placebo-controlled prevalence study. Spine 1996;21:1737-1745.

88. Travell J: Myofascial trigger points. Clinical view. In: Advances in pain research and therapy. Bonica JJ, Able-Fessardi D (eds). Vol 1. New York, Raven Press, 1976, pp 919-926.

89. Skootsky SA, Jaeger B, Oye RK: Prevalence of myofascial pain in general internal medicine practice. West J Med 1989;151:157-160.

90. Han SC, Harrison P: Myofascial pain syndrome and trigger point management. Reg Anesth 1997;22(1):89-101.
91. Barnsley L, Lord S, Bogduk N: Whiplash injury. Pain 1994;58:238-307.

92. Fricton JR: Myofascial pain and whiplash. Teasell R, Shapiro A (eds). Spine. State of the Art Reviews. Cervical flexion - extension injuries. Philadelphia: Hanley \& Belfus, 1993;7:pp403-422.

93. Wolfe F, Simons DG, Fricton J, et al: The fibromyalgia and myofascial pain syndromes. A preliminary study of tender point and trigger points in persons with fibromyalgia pain and no disease. J. Rheumatol 1992;19:944-951.

94. Bogduk N, Simons DG: Neck pain: joint pain or trigger points. In: Vaeroy $\mathrm{H}$ and Merskey $\mathrm{J}$ (Eds) Progress in fibromyalgia and myofascial pain, Amsterdam, Elsevier 1993;pp267-273.

95. Bogduk N: Musculoskeletal pain: toward precision diagnosis. Progress in Pain Research and Management. In: Jensen TS, Turner JA, Wiesenfeld-Hallin Z (eds) Proceedings of the 8th World Congress on Pain, IASP Press (C), Seattle, 1997;pp507-525.

96. Kappis M: Ueber leitungsanasthesie an Bauch, Burst, Arm und Hals durch Injektion ans Foramen intervertebrale. Munch Med Wochenschr 1912;1:794.

97. Wertheim HM, Rovenstine EA: Suprascapular nerve block. Anesthesiology 1941;2:541.

98. Rovenstein EA, Wertheim HM: Therapeutic nerve block. JAMA 1941;117:1599-1603.

99. Ruben JE: Experience with a pain clinic. Anesthesiology 1951;5:574-582.

100. Simmons DQ, Travell JG: The myofascial genesis of pain. Post Grad Med 1952;11:425-434.

101. Okada K: Studies on the cervical facet joints using arthrography of the cervical facet joint. J Jpn Orthop Assoc 1981;55:563-580.

102. Dory MA: Arthrography of the cervical facet joints. Radiology 1983;148:379-382.

103. Barnsley L, Bogduk N: Medial branch blocks are specific for the diagnosis of cervical zygapophyseal joint pain. Reg Anesth 1993;18:343-350.

104. Fox AJ, Melzack R: Transcutaneous electrical stimulation to acupuncture: Comparison of treatment of low back pain. Pain 1976;2:141-148.

105. Fink, BR, Cairns AM: Differential use-dependent (frequency-dependent) effects in single mammalian axons: data and clinical considerations. Anesthesiology 1987;67:477-484.

106. Li Yue-Ming, Wingrove DE, Too HP, et al: Local anesthetics inhibit substance $\mathrm{p}$ binding and evoked increases in intracellular $\mathrm{CA}^{2+}$. Anesthesiology 1995;82:166-173. 
107. Fowler RJ, Blackwell GJ: Anti-inflammatory steroids induced biosynthesis of a phospholipase $\mathrm{A}_{2}$ inhibitor which prevents prostaglandin generation. Nature 1979;278:456-459.

108. Devor M, Govrin-Lippmann R, Raper P: Corticosteroids suppress ectopic neural discharges originating in experimental neuromas. Pain 1985;22:127-137.

109. Hua SY, Chen YZ: Membrane receptor-mediated electrophysiological effects of glucocorticoid on mammalian neurons. Endocrinology 1989;124:687-691.

110. Johansson A, Hao J, Sjolund B: Local corticosteroid application blocks transmission in normal nociceptor C-fibers. Acta Anaesthesiol Scan D 1990;34:335-338.

111. Faber LE, Wakim NG, Duhring JL: Evolving concepts in the mechanism of steroid action: current developments. Am J Obstet Gynecol 1987; 156:1449-1458.

112. Nicol GD, Klingberg DK, Vasko MR: Thoracic epidural with local anesthetic and steroids. Enhances calcium conductance and stimulates release of substance $\mathrm{P}$ in avian sensory neurons. $J$ Neurosci 1992;12:1917-1927.

113. Lee HM, Weinstein JN, Meller ST, et al: The role of steroids and their effects on phospholipase A2. An animal model of radiculopathy. Spine 1998;23:1191-1196.

114. Olmarker K, Byrod G, Cornefijord M, et al: Effects of methylprednisolone on nucleus pulposus-induced nerve root injury. Spine 1994;19:1803-1808.

115. Hayashi N, Weinstein JN, Meller ST, et al: The effect of epidural injection of betamethasone or bupivacaine in a rat model of lumbar radiculopathy. Spine 1998;23:877-885.

116. Waddell G, Turk DC: Clinical assessment of low back pain. In: Handbook of pain assessment. First Edition. Turk DC, Melzack, R (Eds). New York, The Guilford Press. 1992;pp15-36.

117. Haldeman S: Failure of the pathological model to predict back pain. Spine 1990;15:718-732.

118. Chabot MC, Montgomery DM: The pathophysiology of axial and radicular neck pain. Semin Spine Surg 1995;7:2-8.

119. Mooney V, Robertson J: The facet syndrome. Clin Orthop 1976;115:149-156.

120. Dusault DG, Nicolet VM: Cervical facet joint arthrography. J Can Assoc Radiol 1985;36:79-80.

121. Hove B, Glydensted C: Cervical analgesia facet joint arthrography. Neuroradiology 1990;32:456459.

122. Roy DF, Fleury J, Fontaine SB et al: Clinical evaluation of cervical facet joint infiltration. J Can
Assoc Radiol 1988;39:118-120.

123. Wedel DJ, Wilson PR: Cervical facet arthrography. Reg Anesth 1985;10:7-11.

124. Kikuchi S, Hasue M, Nishiyama K: Anatomic and clinical studies of radicular symptoms. Spine 1984:9:23-30.

125. Kikuchi S: Anatomical and experimental studies of nerve root infiltration. Nippon Seikeigeka Gakkai Zasshi (Japan) 1985;56(7):605-614.

126. Kikuchi S, Macnab I, Moreau P: Localization of the level of symptomatic cervical disc degeneration. J Bone Joint Surg 1981;63:272-277.

127. Wilkinson HA, Schuman N: Intradiscal corticosteroids in the treatment of lumbar and cervical disc problems. Spine 1980;5:385-389.

128. Racz GB, Holubec JT: Lysis of adhesions in the epidural space. In: Techniques of neurolysis. Racz GB (eds). Boston, Kluwer Academic Publishers; 1989:pp57-72.

129. Bogduk N, Aprill C, Derby R: Diagnostic blocks of synovial joints. In: White AH, Schofferman JA (eds). Spine Care: diagnosis and conservative treatment. Volume 1. St. Louis: Mosby, 1995:298-321.

130. Lord SM, Barnsley L, Bogduk N: The utility of comparative local anesthetic blocks versus placebo-controlled blocks for the diagnosis of cervical zygapophysial joint pain. Clin J Pain 1995;11:208-213

131. Barnsley L, Lord SM, Bogduk N: Comparative local anesthetic blocks in the diagnosis of cervical zygapophysial joints pain. Pain 1993;55:99-106.

132. Barnsley L, Lord SM, Wallis BJ, et al: False-positive rates of cervical zygapophysial joint blocks. Clin J Pain 1993;9:124-130.

133. Barnsley L, Lord SM, Wallis BJ, et al: Lack of effect of intra-articular corticosteroids for chronic pain in the cervical zygapophyseal joints. $N$ Engl JMed 1994;330:1047-1050.

134. Bovim G, Berg R, Dale LG: Cervicogenic headache: anesthetic blockades of cervical nerves (C2C5) and facet joint (C2/C3). Pain 1992;49:315320.

135. Fukusaki M, Tsuji K, Fujie T, et al: The effects of blockade of the facet joint of the Atlas and Axis upon muscle tension headaches. Headache 1990;4:312-317.

136. Bogduk N, Macintosh J, Marsland A: Technical limitations to the efficacy of radiofrequency neurotomy for spinal pain. Neurosurgery 1987;20:529535.

137. Lord SM, Barnsley L, Bogduk N: Percutaneous radiofrequency neurotomy in the treatment of cervical zygapophyseal joint pain: a caution. $\mathrm{Neu}$ - 
rosurgery 1995;35:732-739.

138. Van Kleef AR, Spaans F, Digemavs W, et al: Effects and side effects of percutaneous thermal lesions of the dorsal root ganglion in patients with cervical pain syndromes. Pain 1993;52:4953.

139. Van Kleef M, Liem L, Lousberg R et al: Radiofrequency lesions adjacent to the dorsal root ganglion for cervicobrachial pain: A prospective double blind randomized study. Neurosurgery 1996;38:1-6.

140. Pawl RP, Anderson W, Shulman M: Effect of epidural steroids in the cervical and lumbar region on surgical intervention for discogenic spondylosis. In: Advances in Pain Research and Therapy, Fields HL, (ed). Vol. 9. New York, Raven Press, 1985;pp791-798.

141. Bush K, Hillier S: Outcome of cervical radiculopathy treated with periradicular/epidural corticosteroid injections: A prospective study with independent clinical review. Eur Spine $J$ 1996;5:319-325.

142. Manchikanti L. Pakanati RR, Bakhit CE, et al: Role of Adhesiolysis and Hypertonic Saline Neurolysis in Management of Low Back Pain. Evaluation of Modification of Racz Protocol. Pain Digest, 1999; 9:91-96.

143. Lewit K: The needle effect in the relief of myofascial pain. Pain 1979;6:83-90

144. Yaeger B, Shootsky SA: Double-blind, controlled study of different myofascial trigger point injection techniques. Pain 1987;31:52-62.

145. Hameroff SR, Crago BR, Blitt CD, et al: Comparison of bupivacaine, etidocaine, and saline for trigger point therapy. Anesth Analg 1981;60:752-755.

146. Hackett GS: Prolotherapy in whiplash and low back pain. Post Graduate Med 1960;Feb;214-219.

147. Hackett GS, Huang TC, Raftery A: Prolotherapy for headache pain in the head and neck, and neuritis. Headache 1962;April:20-28.

148. Kayfetz DO, Blumenthal LS, Hackett GS, et al: Whiplash injury and other ligamentous headache - its management with prolotherapy. Headache 1963:April:21-28.

149 Wilkinson HA: The failed back syndrome. Etiology and therapy. $2^{\text {nd }}$ edition. New York, SpringerVerlag, 1992;pp144-172.

150. Smith G, Nichols P: The technique of cervical discography. Radiology 1957;68:718-720.

151. Hirsch C, Schajowicz F, Galante J: Structural changes in the cervical spine. Acta Orth Scand 1967;109:68-72.

152. Smith G: The normal discogram. Am J Radiol 1959;81:1006-1010.
153. Holt E: Fallacy of cervical discography. JAMA 1964;188:799-801.

154. Parfenchuck T, Janssen M: A correlation of cervical magnetic resonance imaging and discographycomputed tomographic discograms. Spine 1994;19:2819-2825.

155. Roth O: Cervical analgesic discography: a new test for the definitive diagnosis of the painfuldisc syndrome. JAMA 1976;235:1713-1714.

156. Shinomiya K, Nakao N, Shindoh K, et al: Evaluation of cervical discography in pain origin and provocation. J Spinal Disord 1993;6:422-426.

157. Simmons E: An evaluation of discography in the localization of symptomatic levels in discogenic diseases of the spine. Clin Orthop 1975;108:5759.

158. Schellhas KP, Smith MD, Gundry CR, et al: Cervical discogenic pain. Spine 1996;21:300-311.

159. The executive committee of the North American Spine Society. Position statement on discography. Spine 1988;13:1343.

160. Boden SD, McCowin PR, Davis DO, et al: Abnormal magnetic-resonance scans of the cervical spine in asymptomatic subjects. J Bone Surg 1990;72A:1178-1184.

161. Whitecloud T, Seago R: Cervical discogenic syndrome: results of operative intervention in patients with positive discography. Spine 1987;12(4):313316.

162. Donner JE, Pettine KA: The diagnosis and surgical treatment of chronic cervical whiplash disc injuries. In: Whiplash injuries. Gunzburg R, Szapalki M (Eds). Philadelphia, Lippincot-Raven, 1997;pp233-240.

163. Van Kleef M, Sluijter M: Initial experience with radiofrequency heating of the intervertebral disc in the treatment of post-traumatic cervical pain. The Pain Clin 1995;1:543-550.

164. Gladstone JC, Pennant JH: Spinal anesthesia following facet joint injection. Anesthesia 1987; 42:754-756.

165. Marks R, Semple AJ: Spinal anesthesia after facet joint injection. Anesthesia 1988; 43:65-66.

166. Lord SM, Barnsley L, Bogduk N: Percutaneous radiofrequency neurotomy in the treatment of cervical zygapophyseal joint pain: a caution. $\mathrm{Neu}$ rosurgery $1995 ; 35: 732-739$.

167. Williams KN, Jackowski A, Evans PJD: Epidural haematoma requiring surgicla decompression following repeated cervical epidural steroid injection for chronic pain. Pain 1990;42:197-199.

168. Bogduk N, Christophidis N, Cherry D, et al: Epidural use of steroids in the management of back pain. Report of working party on epidural use of 
steroids in the management of back pain. $\mathrm{Na}$ tional Health and Medical Research Council, Commonwealth of Australia, Canberra 1994;pp1-76.

169. Manchikanti L. The role of neural blockade in the management of chronic low back pain. Pain Digest 1999; 9:166-181.

170. Bromage PR: Complications and contraindications. In: Bromage PR, (Ed) Epidural Analgesia. Philadelphia, WB Saunders, 1978;pp469-471.

171. Bromage PR, Benumof JL: Paraplegia following intracord injection during attempted epidural anesthesia under general anesthesia. Reg Anesth 1998; 23:104-107.

172. Hodges SD, Castleberg RL, Miller T, Ward R, Thornburg C: Cervical epidural steroid injection with intrinsic spinal cord damage. Two case reports. Spine 1998; 23:2137-2142.

173. Dawkins CJM: An analysis of the complications of extradural and caudal block. Anaesthesia 1980;35:593-594.

174. Waldman SD: Complications of cervical epidural nerve blocks with steroids. A prospective study of 790 consecutive blocks. Reg Anesth 1989;14:149-151.

175. Derby R. Cervical epidural steroid injections. Point of view. Spine 1998 23:2141-2142.

176. Manchikanti L. Comment on cervical epidural steroid injections with intrinsic spinal cord damage. Spine 1999; 24:170-171.

177. Slipman CW, Plastaras CT, Palmitier RA, Huston CW, Sterenfeld EB. Symptoms of provocation of fluoroscopically guided cervical nerve root stimulation. Spine 1998; 23:2235-2242.

177B. Waldman SD: Cervical epidural abscess after cervical epidural nerve block with steroids. Anesth Analg 1991;72:717-718.

178. Bromage PR: Spinal extradural abscess: Pursuit of vigilance. Brit J Anaesth 1993;70:471-473.

179. Strong WE: Epidural abscess associated with epidural catheterization: A rare event? Report of two cases with markedly delayed presentation. Anesthesiology 1991;74:943-946.

180. Bollensen E, Prange HW: An epidural spinal abscess as a lethal complication of peridural anesthesia. Reg Anaesth 1991;14:101-103.

190. Schaerer JP: Cervical discography. J Int Coll Surg 1964;42:287-296.

191. Schiller F, Shadle OW: Extrathecal and intrathecal suppuration. Arch Neurol 1962;7:33-36.

192. Vogelsang H: Discitis intervertebralis cervicalis nach diskographie. Neurochirurgia 1973;16:8083.

193. Delaney TJ, Rowlingson JC, Carron H, et al: Epi- dural steroid effects on nerves and meninges. Anesth Analg 1980;58:610-614.

194. Cicala RS, Turner R, Moran, E, et al: Methylprednisolone acetate does not cause inflammatory changes in the epidural space. Anesthesiology 1990;72:556-558.

195. MacKinnon SE, Hudson AR, Gentili R, et al: Peripheral nerve injection injury with steroid agents.

Plast Reconstr Surg 1982;69:482-489.

196. Chino N, Awad EA, Kottke FJ: Pathology of propylene glycol administered by perineural and intramuscular injection in rats. Arch Phys Med Rehab 1974;55:33-38.

197. Benzon HT, Gissen AJ, Strichartz GR, et al: The effect of polyethylene glycol on mammalian nerve impulses. Anesth Analg 1987;66:553-559.

198. Abram SE, Marsala M, Yaksh TL: Analgesic and neurotoxic effects of intrathecal corticosteroids in rats. Anesthesiology 1994;81:1198-1205.

199. Latham JM, Fraser RD, Moore RJ, et al: The pathologic effects of intrathecal betamethasone. Spine 1997;22:1158-1162.

200. Wilkinson HA: Intrathecal DepoMedrol: a literature review. Clin J Pain 1992;8:49-56.

201. Slucky AV, Sacks MS, Pallares VS, et al: Effects of epidural steroids on lumbar dura material properties. Journal of Spinal Disorders 1999; 12:331340 .

202. Knight CL, Burnell JC: Systemic side-effects of extradural steroids. Anaesthesia 1980;35:593-594.

203. Edmonds LC, Vance ML, Hughes JM: Morbidity from paraspinal depo-corticosteroid injections for analgesia: cushing's syndrome and adrenal suppression. Anesth Analg 1991;72:820-822.

204. Mikhail GR, Sweet LC, Mellinger RC: Parental longacting corticosteroid effect on hypothalamic pituitary adrenal function. Ann Allergy 1973;31:337343.

205. Mikhail GR, Livingood CS, Mellinger RC, et al: Effect of long-acting parenteral corticosteroids on adrenal function. Arch Dermatol 1969;100:263268.

206. McEvoy GK, Utvak K, Welsh OH: AHFS 96 drug information. Bethesda, American Society of Health-System Pharmacists, 1996;pp2216-2243.

207. Schimmer BP, Parker KI: Adrenocorticotropic hormone; adrenocortical steroids and their synthetic analogs; inhibitors of the synthesis and actions of adrenocortical hormones. In: Hardman JG, Molinoff PB, Ruddon RW (eds) Goodman's \& Gilman's: The pharmacological basis of therapeutics; 9th edition, New York, Mcgraw-Hill, 1996;pp1459-1485.

208. Melby JC: Drug spotlight program: Systemic cor- 
ticosteroid therapy; pharmacologic and edocrinologic considerations. Ann Inter Med 1974;81:505-512.

209. Roonen S, Van Distel G, Westhovens R, et al: Steroid myopathy induced by epidural triamcinolone injection. Brit J Rheumatol 1995;34(4):385.

210. Roy-Camille R, Mazel CH, Husson JL, et al: Symptomatic spinal epidural lipomatosis induced by a long-term steroid treatment. Spine 1991;16:13651371.

211. Kusher FH, Olson JC: Retinal hemorrhage as a consequence of epidural steroid injection. Arch Ophthal 1995;113:309-313.

212. Lilius G, Harilainene A, Laasonen EM, et al: Chronic unilateral low-back pain. Predictors of outcome of facet joint injections. Spine 1990;15:780-782.

213. Lilius G, Laasonen EM, Myllynen P, et al: Lumbar facet joint syndrome. Significance of non-organic signs. A randomized placebo-controlled clinical study. Rev Chir Orthop 1989;7:493-500.

214. Ferrante FM, Wilson SP, Lacobo C, et al: Clinical classification as a predictor of therapeutic outcome after cervical epidural steroid injection. Spine 1993;18:730-736.

215. Cicala RS, Wright H: Outpatient treatment of patients with chronic pain. Analysis of cost sav- ings. Clin J Pain 1989;5:223-226.

216. Mueller-Schwefe G, Hassenbusch SJ, Reig E. Cost effectiveness of intrathecal therapy for pain. Neuromodulation 1999; 2:77-84.

217. Malter AD, Larwon EB, Urban N, et al: Cost-effectiveness of lumbar discectomy for the treatment of herniated intervertebral disc. Spine 1996;21:1048-1055.

218. Manchikanti L, Pakanati RR, Pampati V: Comparison of Three Routes of Epidural Steroid Injections in Low Back Pain. Pain Digest 1999; 9:277285.

219. Manchikanti L, Pakanati RR: Non-Endoscopic and Endoscopic Adhesiolysis in Post Lumbar Laminectomy Syndrome. A One-Year Outcome Study and Cost Effectiveness Analysis. Pain Physician 1999; 2: 52-58.

220. Sanders SH, Brena SF: Pain centers: what consumers want to know. American Pain Society Bull 1995;5:8-11.

221. Arnoff GM: Where have we been? Where are we now? Where are we going.(Editorial) Clin J Pain 1997; 13:3-5

222. Jacobsen L, Mariano A, Chabal C, et al: Beyond the needle: Expanding the role of anesthesiologists in the management of chronic non-malignant pain. Anesthesiology 1997;87:1210-1218. 